\section{Self-Assembly of an Interlaced Triple-Stranded Molecular Braid with an Unprecedented Topology through Hydrogen-Bonding Interactions***}

\author{
Xin-Jun Luan, Yao-Yu Wang, * Dong-Sheng Li, \\ Ping Liu, Huai-Ming Hu, Qi-Zhen Shi, and \\ Shie-Ming Peng
}

The current interest in the crystal engineering of coordination polymers ${ }^{[1]}$ stems from their potential applications as materials $^{[2]}$ for molecular selection, ion exchange, and catalysis, as well as because of their intriguing variety of architectures and topologies. Many recent examples have illustrated that topological types unprecedented in inorganic compounds

[*] X.-J. Luan, Prof. Dr. Y.-Y. Wang, Dr. D.-S. Li, Dr. P. Liu, Prof. Dr. H.-M. Hu, Prof. Dr. Q.-Z. Shi

Department of Chemistry

Shaanxi Key Laboratory of Physico-Inorganic Chemistry Northwest University

Xi'an, Shaanxi, 710069 (P.R. China)

Fax: (+86) 29-8837-3398

E-mail:wyaoyu@nwu.edu.cn

Prof. Dr. S.-M. Peng

Department of Chemistry

National Taiwan University (Taiwan)

[*:*] This work was supported by the National Natural Science Foundation of China (No. 20471048) and TRAPOYT. and in minerals can be observed within coordination polymer frameworks. ${ }^{[3]}$ Particularly attractive is the finding of species with novel modes of supramolecular intertwining, such as helices, rotaxanes, catenanes, and knots, ${ }^{[4]}$ which contribute more and more to our increasing knowledge of the selfassembly processes and the supramolecular self-organization of coordination polymers. The amount of predefined information can be reduced by incorporating a higher degree of flexibility into the building blocks, and more unpredictable structures can arise from identical metal-ligand combinations. For example, rigid polyfunctional ligands are well known to form grids, ${ }^{[5]}$ brick-wall structures, ${ }^{[6]}$ honeycombs, ${ }^{[7]}$ diamondoid nets, ${ }^{[8]}$ and other noteworthy species, ${ }^{[9]}$ while long flexible polyfunctional ligands have shown the ability to produce unique interwoven extended structural motifs, such as polycatenanes, ${ }^{[10]}$ polyrotaxanes,${ }^{[11]}$ double helices,${ }^{[12]}$ triple helices, ${ }^{[13]}$ and other uncommon species. ${ }^{[14]}$ Some of the interwoven structures may be predictable; however, structural control of metal-organic reactions (especially those involving flexible ligands) remains a great challenge, and unexpected structures with unprecedented topologies often result. Herein we report a fascinating interlaced triplestranded braid based on a $\mathrm{Cu}^{\mathrm{II}}$ complex with the highly flexible 1,3-bis(4-pyridyl)propane (bpp) ligand. To the best of our knowledge, this species presents a remarkable and unprecedented topology of a triple-stranded molecular braid which looks just like a hair plait. Moreover, it shows an interesting behavior in which the interlaced chains are selfrecognized by hydrogen bonds between them.

Slow evaporation of the methanol/acetonitrile solvent from a solution of bpp and $\left[\mathrm{Cu}_{2}(\mathrm{maa})_{4} \cdot 2 \mathrm{H}_{2} \mathrm{O}\right](\mathrm{Hmaa}=2$ methylacrylic acid) in a 2:1 stoichiometry led to crystals of $\left[\mathrm{Cu}_{4}(\mathrm{bpp})_{4}(\mathrm{maa})_{8}\left(\mathrm{H}_{2} \mathrm{O}\right)_{2}\right] \cdot 2 \mathrm{H}_{2} \mathrm{O}(\mathbf{1})$.

The structure of $\mathbf{1}$ was determined unambiguously by $\mathrm{X}$ ray crystallographic analysis. ${ }^{[15]}$ This system crystallized in the centrosymmetric space group $\mathrm{P} \overline{1}$, with three independent copper centers per asymmetric unit (Figure 1). Each $\mathrm{Cu}^{\mathrm{II}}$ center has a different coordination environment: distorted square pyramid, ideal square-planar, and distorted octahedral geometries. Although it is well known that $\mathrm{Cu}^{\mathrm{II}}$ ions can give rise to tetracoordinate, pentacoordinate, and hexacoordinate geometries, complexes in which the three coordination styles all exist hasn't been reported to date. The complex reported herein contains the three modes of coordination for $\mathrm{Cu}^{\mathrm{II}}$ ions in the arrangement $\left(-\mathrm{Cu}^{5}-\mathrm{Cu}^{6}-\mathrm{Cu}^{5}-\mathrm{Cu}^{4}-\right)_{n}\left(\mathrm{Cu}^{x}, x=\right.$ coordination number). In addition, the terminally coordinated maa anions exhibit a versatile coordination behavior and display different bonding modes with the copper cations: monodentate for $\mathrm{Cu} 1$ and $\mathrm{Cu} 2$ and chelating for $\mathrm{Cu} 3$. In the complex, bpp is employed as a bridging ligand for the construction of a one-dimensional chain along the $c$ axis which has alternating helical sections (alternating right and left turns of the strand when looking down the "growth axis"). However, the single strand chain is not a helical structure, because the strand contains centers of inversion and does not have defined chirality. Interestingly, bpp can adopt different conformations with respect to the relative orientations of the $\mathrm{CH}_{2}$ groups: the bpp ligand between $\mathrm{Cu} 1$ and $\mathrm{Cu} 2$ adopts a trans-gauche (TG) conformation, in which $\mathrm{N} \cdots \mathrm{N}$ is 8.684(2) $\AA$, whereas the 


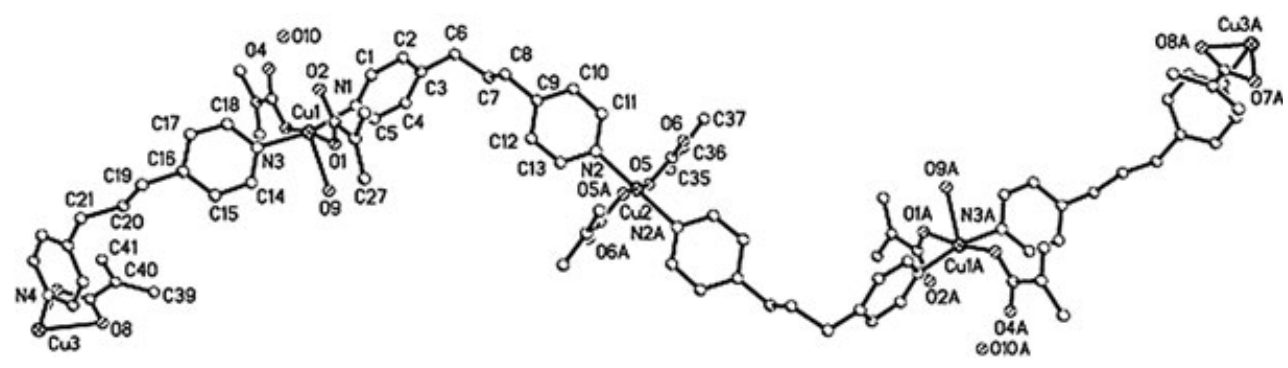

Figure 1. A view of the coordination environments at the three $\mathrm{Cu}$ " centers in 1. Selected bond lengths [Å]: Cu1-O1 1.918(2), Cu1-O3 1.920(2), Cu1-O9 2.329(2), Cu1-N1 2.027(2), Cu1-N3 2.026(3), Cu2-O5 1.991(2), Cu2-N2 1.995(3), Cu3-O7 2.111(3), Cu3-O8 2.361(3), Cu3-N4 1.985(2).

bpp ligand between $\mathrm{Cu} 1$ and $\mathrm{Cu} 3$ adopts a TT conformation, in which $\mathrm{N} \cdots \mathrm{N}$ is longer $(9.375(2) \AA)$. The chain in $\mathbf{1}$, therefore, results from metal-ligand interactions coupled with various other factors and can be described as $\left(-b p p^{T T}\right.$. $\left.\mathrm{Cu}^{5}-\mathrm{bpp}^{\mathrm{TG}}-\mathrm{Cu}^{6}-\mathrm{bpp}^{\mathrm{TG}}-\mathrm{Cu}^{5}-\mathrm{bpp}^{\mathrm{TT}}-\mathrm{Cu}^{4}-\right)_{n}$. The periodicity of the chain is $44.280(2) \AA$ and contains four $\mathrm{Cu}^{\mathrm{II}}$ centers per repeat unit.

The crystal structure of $\mathbf{1}$ shows the presence of a neutral interlaced triple-stranded braid, which is formed by the interweaving of three single-stranded chains with alternating helical parts that extend along the $c$ axis (Figure 2). The repeat distance of the braid $(14.760 \AA)$ is $1 / 3$ of the repeat distance of the single chain. $\mathrm{Cu}^{\mathrm{II}}$ atoms are arranged in a line in the middle of the braid, and the distance between the adjacent $\mathrm{Cu}^{\mathrm{II}}$ centers is $7.380 \AA$, which is half of the repeat distance of the braid. Discrete triple-stranded intertwining chains generally show a triple-helix topology in supramolec- ular chemistry. ${ }^{[13]}$ In contrast, the structure of $\mathbf{1}$ can be described as a molecular braid with an unprecedented topology. To the best of our knowledge, this is the first example of a molecular braid which mimics perfectly a hair plait. Careful examination of the structure indicates that strong intermolecular hydrogen bonds of O9-H9A $\cdots \mathrm{O} 8$

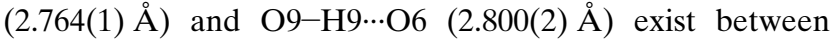
the three independent chains in the braid (Figure 3 ). It is clear that two hydrogen atoms of one coordinated water molecule serve as the acceptors, while the two oxygen atoms of different coordinated maa anions serve as the donors in each self-recognition site. Self-recognition often operates between groups during the assembly of amino acid molecules in crystals, in the majority of cases, through the formation of hydrogen bonds. In the current complex, the molecular braid structure can be considered to be dependent on self-recognition between the three chains. That is, the hydrogen bonds,

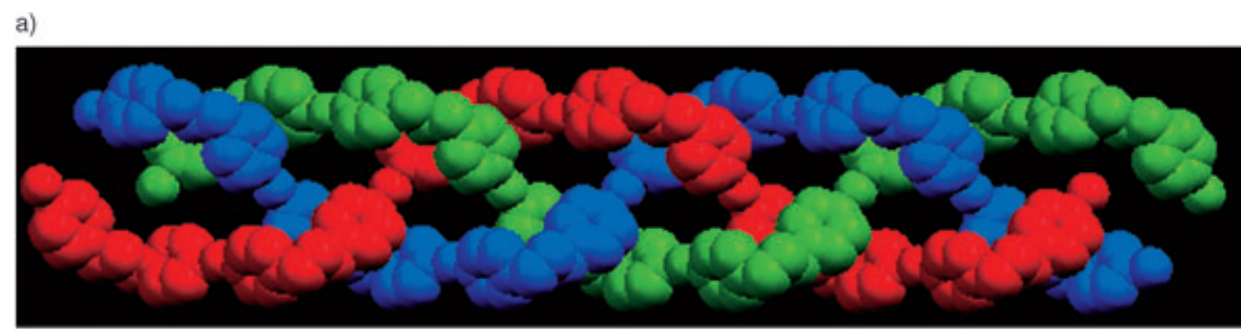

b)

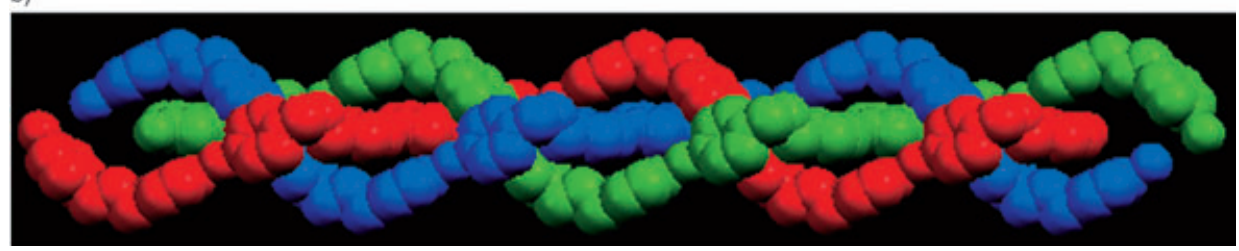

Figure 2. a) Top view of the interlaced triple-stranded braid of 1 and b) side view of 1 . The maa anions are omitted for clarity, and the triplestranded chains are colored red, blue, and green.

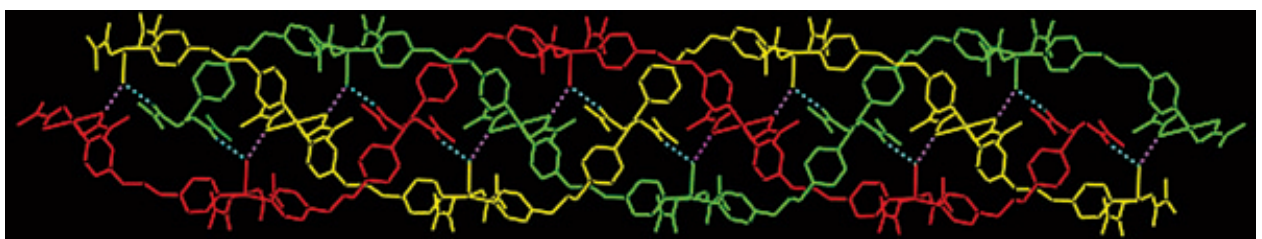

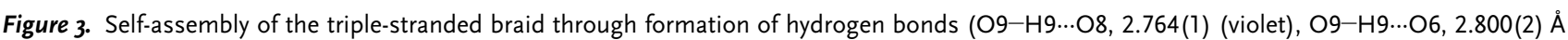
(light blue)). 
through which the molecular braid is aligned exactly, operate between the three interwoven chains. Thus, the formation of the molecular braid in this case is expected to occur in two steps: initial construction of an infinite interwoven chain of ligated $\mathrm{Cu}^{\mathrm{II}}$ ions, followed by hydrogen-bonding between the infinite chains. Thermogravimetric analysis (TGA) of the crystalline complexes $\mathbf{1}$ showed that after the loss of uncoordinated water molecules $(2.0 \%)$ below $65^{\circ} \mathrm{C}$, no weight loss occurred until approximately $235^{\circ} \mathrm{C}$, which indicates the molecular braid is thermally stabile. Detailed analysis of the crystal structure also indicates that the main factor governing this phenomenon is not only the hydrogen bonds between the chains, as expected, but also by the braid framework, that is, by the interweaving of the single polymeric strands (which have alternating right and left turns looking down the "growth axis"). The rigidity of the braid framework means that the braids cannot approach one another sufficiently closely in the crystal; thus, the framework promotes the formation of an interlaced triple-stranded braid.

Another interesting structural feature of $\mathbf{1}$ is that there are many uncoordinated oxygen atoms that become arranged along the two sides on formation of the braid. In the process of self-assembly, uncoordinated oxygen atoms can act as hydrophilic sites and easily form hydrogen bonds with water molecules that approach the host (O10-H10A $\cdots \mathrm{O} 2$

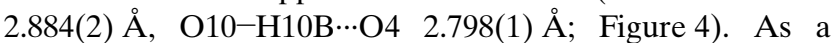
result, guest water molecules seem to cling to the surface of the braid.

In conclusion, the results demonstrate that an unusual complex comprising an interlaced triple-stranded braid is synthesized from the reaction of a $\mathrm{Cu}^{\mathrm{II}}$ complex having a paddle-wheel structure with a flexible neutral organic ligand in the ratio of $1: 2$, which is different to the typical reaction route. ${ }^{[16]}$ To the best of our knowledge, this complex-ligand combination represents a unique case in which the supramolecular assembly results in a molecular braid with an unprecedented topology. This example thus brings a new member to the family of suprastructures composed of identical units.

\section{Experimental Section}

$\left[\mathrm{Cu}_{2}(\mathrm{maa})_{4}\right] \cdot 2 \mathrm{H}_{2} \mathrm{O}$ : Reaction of $\left[\mathrm{Cu}_{2}(\mathrm{OH})_{2} \mathrm{CO}_{3}\right](2.211 \mathrm{~g}, 10 \mathrm{mmol})$ with 2-methylacrylic acid $(3.442 \mathrm{~g}, 40 \mathrm{mmol})$ in methanol under reflux for $2 \mathrm{~h}$ afforded blue-green crystals of $\left[\mathrm{Cu}_{2}(\mathrm{maa})_{4} \cdot 2 \mathrm{H}_{2} \mathrm{O}\right.$ in approximately $87 \%$ yield. Elemental analysis calcd $(\%)$ for $\mathrm{C}_{16} \mathrm{H}_{24} \mathrm{Cu}_{2} \mathrm{O}_{10}$ : C 38.17, H 4.80; found: C 38.28, H 4.83. IR (KBr): $\tilde{v}=2968,2932,1681$, 1645, 1594, 1497, 1414, 1299, 1225, 1008, 951, 856, 826, 638, $445 \mathrm{~cm}^{-1}$.
1: A solution of bpp $(0.040 \mathrm{~g}, 0.200 \mathrm{mmol})$ in acetonitrile $(10 \mathrm{~mL})$ was added to a solution of $\mathrm{Cu}_{2}(\mathrm{maa})_{4} \cdot 2 \mathrm{H}_{2} \mathrm{O}(0.050 \mathrm{~g}, 0.100 \mathrm{mmol})$ in methanol $(10 \mathrm{~mL})$. The clear mixture was stirred for a few minutes and then allowed to evaporate at room temperature. Well-shaped blue needles of $\mathbf{1}$ appeared after several days. The crystalline product was filtered, washed with ethanol, and dried in air. Yield, $65 \%$. Elemental analysis calcd for $\mathrm{C}_{84} \mathrm{H}_{104} \mathrm{Cu}_{4} \mathrm{~N}_{8} \mathrm{O}_{20}$ : C 56.05, H 5.82, N 6.22; found: C 56.12, H 5.85, N 6.28. IR (KBr): $\tilde{v}=3421,2953,1650$, $1618,1591,1453,1427,1379,1232,939,835,810,627,523 \mathrm{~cm}^{-1}$.

Received: February 28, 2005

Published online: May 13, 2005

Keywords: coordination polymers · copper - self-assembly supramolecular chemistry · topology

[1] a) B. F. Hoskins, R. Robson, J. Am. Chem. Soc. 1990, 112, 1546; b) O. M. Yaghi, H. Li, C. Davis, D. Richardson, T. L. Groy, Acc. Chem. Res. 1998, 31, 474; c) S. R. Batten, R. Robson, Angew. Chem. 1998, 110, 1558; Angew. Chem. Int. Ed. 1998, 37, 1460; d) F. M. Tabellion, S. R. Seidel, A. M. Arif, P. J. Stang, Angew. Chem. 2001, 113, 1577; Angew. Chem. Int. Ed. 2001, 40, 1529; e) O. M. Yaghi, M. O'Keeffe, N. W. Ockwig, H. K. Chae, M. Eddaoudi, J. Kim, Nature 2003, 423, 705.

[2] a) C. Janiak, Angew. Chem. 1997, 109, 1499; Angew. Chem. Int. Ed. Engl. 1997, 36, 1431; b) D. M. L. Goodgame, D. A. Grachvogel, D. J. Williams, Angew. Chem. 1999, 111, 217; Angew. Chem. Int. Ed. 1999, 38, 153; c) M. Eddaoudi, J. Kim, N. Rosi, D. Vodak, J. Wachter, M. O'Keeffe, O. M. Yaghi, Science 2001, 295, 469; d) R. Matsuda, R. Kitaura, S. Kitagawa, Y. Kubota, T. C. Kobayashi, S. Horike, M. Takata, J. Am. Chem. Soc. 2004, 126, 14063.

[3] a) L. Carlucci, G. Ciani, P. Macchi, D. M. Proserpio, Chem. Commun. 1998, 1837; b) M. J. Zaworotko, Chem. Commun. 2001, 1; c) M. L. Tong, X. M. Chen, S. R. Batten, J. Am. Chem. Soc. 2003, 125, 16170; d) X. H. Bu, M. L. Tong, H. C. Chang, S. Kitagawa, S. R. Batten, Angew. Chem. 2004, 116, 194; Angew. Chem. Int. Ed. 2004, 43, 192.

[4] J.-M. Lehn, Supramolecular Chemistry, VCH, Weinheim, 1995.

[5] a) M. Fujita, Y. J. Kwon, S. Washizu, K. Ogura, J. Am. Chem. Soc. 1994, 116, 1151; b) L. R. MacGillivray, R. H. Groeneman, J. L. Atwood, J. Am. Chem. Soc. 1998, 120, 2676.

[6] M. Fujita, Y. J. Kwon, O. Sasaki, K. Yamaguti, K. Ogura, J. Am. Chem. Soc. 1995, 117, 7287.

[7] a) G. B. Gardner, D. Venkataraman, J. S. Moore, S. Lee, Nature 1995, 374, 792; b) S. R. Batten, B. F. Hoskins, B. Moubaraki, K. S. Murray, R. Robson, Chem. Commun. 2000, 1095.

[8] a) L. R. MacGillivray, S. Subramanion, M. J. Zaworotko, J. Chem. Soc. Chem. Commun. 1994, 1325; b) O. M. Yaghi, H. Li, J. Am. Chem. Soc. 1995, 117, 10401; c) O. R. Evans, R. G. Xiong, Z. Y. Wang, G. K. Wong, W. B. Lin, Angew. Chem. 1999, 111, 557; Angew. Chem. Int. Ed. 1999, 38, 536.

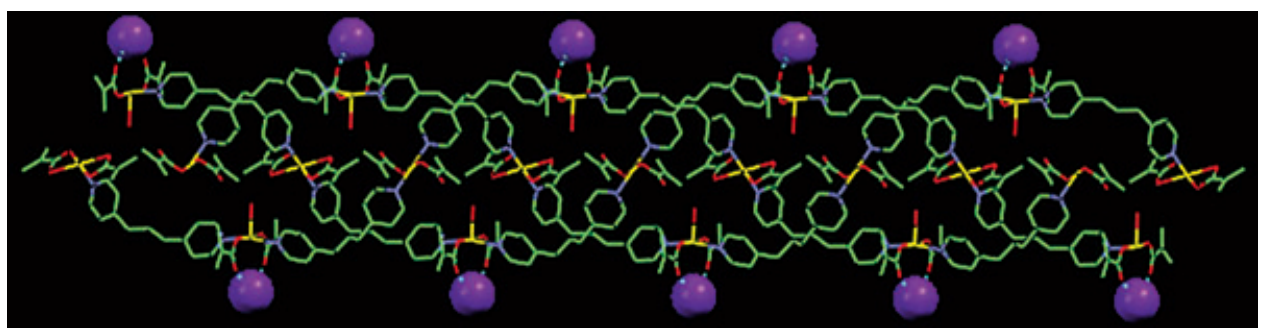

Figure 4. The triple-stranded-braid polymer of 1 with water guest molecules shown as space-filling models. 
[9] a) M. Eddaoudi, J. Kim, M. O'Keeffe, O. M. Yaghi, J. Am. Chem. Soc. 2002, 124, 376; b) B. Moulton, H. Abourahma, M. W. Bradner, J. J. Lu, G. J. McManus, M. J. Zaworotko, Chem. Commun. 2003, 1342; c) X. L. Wang, C. Qin, E. B. Wang, Y. G. Li, C. W. Hu, L. Xu, Chem. Commun. 2004, 378.

[10] a) D. M. L. Goodgame, S. Menzer, A. M. Smith, D. J. Williams, Angew. Chem. 1995, 107, 605; Angew. Chem. Int. Ed. Engl. Angew. Chem. Int. Ed. 1995, 34, 574; b) A. J. Blake, N. R. Champness, A. Khlobystov, D. A. Lemenovkii, W. S. Li, M. Schröder, Chem. Commun. 1997, 2027; c) L. Carlucci, G. Ciani, M. Moret, D. M. Proserpio, S. Rizzato, Angew. Chem. 2000,112, 1566; Angew. Chem. Int. Ed. 2000, 39, 1506; d) L. Carlucci, G. Ciani, D. M. Proserpio, CrystEngComm 2003, 5, 269.

[11] a) D. Whang, K. Kim, J. Am. Chem. Soc. 1997, 119, 451; b) B. F. Hoskins, R. Robson, D. A. Slizys, J. Am. Chem. Soc. 1997, 119, 2952; c) M. L. Tong, Y. M. Wu, J. Ru, X. M. Chen, H. C. Chang, S. Kitagawa, Inorg. Chem. 2002, 41, 4846; d) I. Poleschak, J. M. Kern, J.-P. Sauvage, Chem. Commun. 2004, 474; e) Q. C. Wang, D. H. Qu, J. Ren, K. C. Chen, H. Tian, Angew. Chem. 2004, 116, 2715; Angew. Chem. Int. Ed. 2004, 43, 2661.

[12] a) L. Carlucci, G. Ciani, D. W. Gudenberg, D. M. Proserpio, Inorg. Chem. 1997, 36, 3812; b) O. Mamula, A. von Zelewsky, T. Bark, G. Bernardinelli, Angew. Chem. 1999, 111, 3129; Angew. Chem. Int. Ed. 1999, 38, 2945; c) X. M. Chen, G. F. Liu, Chem. Eur. J. 2002, 8, 4811.

[13] a) D. M. Ciurtin, N. G. Pschirer, M. D. Smith, U. H. F. Bunz, H. C. zur Loye, Chem. Mater. 2001, 13, 2743; b) P. Grosshans, A. Jouaiti, V. Bulach, J. M. Planeix, M. W. Hosseini, J. F. Nicoud, Chem. Commun. 2003, 1336; c) Y. Cui, H. L. Ngo, W. B. Lin, Chem. Commun. 2003, 1388.

[14] a) D. M. L. Goodgame, S. Menzer, A. M. Smith, D. J. Williams, Chem. Commun. 1997, 339; b) T. Y. Niu, X. Q. Wang, A. J. Jacobson, Angew. Chem. 1999, 111, 2059; Angew. Chem. Int. Ed. 1999, 38, 1934; c) L. Carlucci, G. Ciani, D. M. Proserpio, L. Spadacini, CrystEngComm 2004, 6, 96; d) L. Carlucci, G. Ciani, D. M. Proserpio, Chem. Commun. 2004, 380.

[15] Crystal data for $\mathbf{1}: \mathrm{C}_{84} \mathrm{H}_{104} \mathrm{Cu}_{4} \mathrm{~N}_{8} \mathrm{O}_{20}$, triclinic, space group $\mathrm{P} \overline{1}, a=$ 12.0997(14), $b=12.8855(16), c=14.7601(17) \AA, \alpha=89.462(2)$, $\beta=86.349(2), \quad \gamma=76.122(2)^{\circ}, \quad V=2229.5(5) \AA^{3}, \quad Z=4, \quad \rho_{\text {calcd }}=$ $1.341 \mathrm{~g} \mathrm{~cm}^{-3}$. In the final least-squares refinement cycles on $|F|^{2}$, the model converged at $R_{1}=0.0397, w R_{2}=0.1041$, and GOF $=1.038$ for 7233 independent reflections $(I>2 \sigma(I))$. The data collections were performed at 293(2) K on a Bruker SMART CCD area-detector diffractometer, using $\mathrm{Mo}_{\mathrm{K} a}$ radiation $(\lambda=0.71073 \AA)$ and the $\omega$-scan method within the limits $1.74<\theta<24.41$. Absorption corrections were made with the program SADABS, ${ }^{[17]}$ and the crystallographic package SHELXTL ${ }^{[18]}$ was used for all calculations. All diagrams were generated using the SHELX-97 and MERCURY programs. CCDC-257085 contains the supplementary crystallographic data for this paper. These data can be obtained free of charge from the Cambridge Crystallographic Data Centre via www.ccdc. cam.ac.uk/data_request/cif.

[16] W. J. Belcher, C. A. Longstaff, M. R. Neckenig, J. W. Steed, Chem. Commun. 2002, 1602.

[17] G. M. Sheldrick, SADABS. Software for empirical absorption corrections, University of Göttingen, Gemany, 2000.

[18] SHELXTL Reference Manual, Version 5.1, Bruker AXS, Analytical X-Ray Systems, Inc., Madison, WI, USA, 1997. 